\title{
Investigation on Flexural Strength Changes of Alumina Caused by Cutting using Fiber Laser
}

\author{
B. Adelmann and R. Hellmann \\ Applied laser and photonics group, University of Applied Sciences Aschaffenburg, \\ Würzburger Str. 45, 64743 Aschaffenburg, Germany \\ E-mail: Benedikt.adelmann@h-ab.de
}

\begin{abstract}
We present a comprehensive experimental study on the influence of laser cutting on the flexural strength of $0.63 \mathrm{~mm}$ thick alumina sheets. In this study ceramic specimens are cut to a size of $24 \times 3$ $\mathrm{mm}^{2}$ with the flexural strength being measured using a 3 point bending test. Based on a design of experiments approach the results reveal that among the experimental parameters the laser focus position has the highest influence on the flexural strength, reducing it by $63 \mathrm{MPa}$. Cutting alumina at $300 \mathrm{~mm} / \mathrm{s}$ yields a flexural strength of $395 \mathrm{MPa}$, which is significantly lower as compared with reference samples produced by scribe and break having a flexural strength of $520 \mathrm{MPa}$. Yet, a comparable flexural strength of $311 \mathrm{MPa}$ using a $\mathrm{CO}_{2}$ laser is achieved at only $20 \mathrm{~mm} / \mathrm{s}$. To cut small contours, digital modulation of the fiber laser output power is employed leading to a flexural strength of $506 \mathrm{MPa}$ at $1 \mathrm{~mm} / \mathrm{s}$ and $469 \mathrm{MPa}$ at $10 \mathrm{~mm} / \mathrm{s}$. Further results show that additional outer contours can halve the flexural strength and the lack of rounding reduces the flexural strength further. Inner contours especially with corners are also decreasing the flexural strength drastically while an inner circle causes only low strength reduction.
\end{abstract}

DOI: $10.2961 / \mathrm{j} l \mathrm{mn} .2014 .02 .0014$

Keywords: Laser cutting, alumina, crack formation, fiber laser, flexural strength

\section{Introduction}

In the last decade there is an increasing demand in ceramic substrates made of alumina for the electronic industry. Electronics on ceramic substrates are found in, e.g., automotive, telecommunication, power electronics and various sensor systems. Ceramic substrates have many advantages over paper and glass fiber reinforced plastics with one of the most important ones being their high thermal conductivity. Standard and frequently used FR4 has a thermal conductivity of $0.3 \mathrm{~W} / \mathrm{mK}$, while alumina is characterized by $25 \mathrm{~W} / \mathrm{mK}$. As a result, the need of additional cooling is reduced when using ceramic substrates [1]. Further advantages of alumina compared to standard FR4 substrates are the chemical inertness and the much higher maximum operation temperature [2].

Due to its high Vickers hardness of 1600 HV1 and brittleness the only mechanical method processing alumina is diamond abrasive cutting [3]. But even diamond grinding tends to result in low processing speeds and high tool wear as well as the danger of mechanical breakup. Therefore, different laser processing strategies are commonly in use. In order to reach high velocities during separating straight lines, mostly $\mathrm{CO}_{2}$ lasers are industrially employed for the scribe and break method [4]. This process has the advantage of a low required laser power and it is possible to run additional manufacturing steps between scribing and breaking.

For more complex contours usually laser fusion cutting is used. Using this technique Black and Chua [5] cut complex contours even in $9.2 \mathrm{~mm}$ thick alumina with a power modulated $530 \mathrm{~W} \mathrm{CO}_{2}$ laser at $1.5 \mathrm{~mm} / \mathrm{s}$ but having major problems with cracks. Hong et al. [6] separated silicon ni- tride ceramics with a $250 \mathrm{~W}$ Q-switched $\mathrm{CO}_{2}$ Laser in a multi-pass process at an effective cutting velocity of $1 \mathrm{~mm} / \mathrm{s}$. In this process a higher velocity of the single passes of about $220 \mathrm{~mm} / \mathrm{s}$ leads to less crack formations. Ji et al. [7] cut $10 \mathrm{~mm}$ thick alumina using a pulsed $\mathrm{CO}_{2}$ laser with $3.5 \mathrm{~kW}$ peak power at $0.3 \mathrm{~mm} / \mathrm{s}$ without breakup of the substrate. Other research topics in laser cutting of ceramics is described by Wee et al. [8] who found that by cutting $7 \mathrm{~mm}$ thick alumina with a $1.2 \mathrm{~kW} \mathrm{CO}$ Laser the striation angle and the striation wavelength are mainly influenced by the laser material interaction time and the gas pressure.

To predict cracks induced by the thermal stress during laser cutting Lee and Ahn [9] developed a Bayesian Probabilistic Model suggesting that cracks mainly depend on the cutting front angle. Another approach to predict cracks was presented by Yilbas et al. [10] using thermal simulations showing that cracks are mainly caused by the resolidification of molten material in the cut kerf. Yan et al. [11] performed experiments cutting $6 \mathrm{~mm}$ thick alumina with a $3.5 \mathrm{~kW} \mathrm{CO}$ Laser at different pulse mode showing that fewer pulses with more energy but large switch off times create less stress than many pulses with lower pulse energy.

To avoid cracks in micro processing ceramics Wang et al. [12] presented results on cutting holes in $0.63 \mathrm{~mm}$ thick alumina substrates using a 150 femtosecond short pulse laser with an average power of $0.8 \mathrm{~W}$ in a multi pass process. The authors achieved very high cutting quality but only an effective velocity of $1.5 \mu \mathrm{m} / \mathrm{s}$, which is much too slow for industrial applications. The use of excimer laser (248 $\mathrm{nm} \mathrm{KrF}$ ) by Lump and Allen [13] in cutting vias into 
$0.63 \mathrm{~mm}$ thick alumina nitride showing good quality but also revealing major problems with cracks. With 3000 pulses for one via at $50 \mathrm{Hertz}$ laser repetition rate the process is also too slow for industrial applications.

The literature reveals that for cutting complex contours or vias in alumina only fusion cutting offers a fast process with high quality. The disadvantage of fusion cutting is, however, the generation of thermal induced stress and cracks leading to the reduction in strength of the material [10]. In this contribution, we examine the influence of laser fusion cutting with a single mode fiber laser on the flexural strength of alumina and maximize the flexural strength by parameter optimization. The results are compared with the flexural strength after separation with scribe and break and with $\mathrm{CO}_{2}$ laser cuts. Further we measure the strength change by cutting inner and outer contours.

\section{Experimental}

\subsection{Laser system}

In this study, a continuous wave $500 \mathrm{~W}$ single mode fiber laser (IPG Photonics) is used for fusion cutting. The laser system is equipped with linear stages $(x, y)$ for the workpiece (Aerotech) and a fine cutting head (Precitec) attached to a linear drive (z). The assisted gas nitrogen with purity greater than $99.999 \%$ flows coaxial to the laser beam. The gas nozzle has a diameter of $0.3 \mathrm{~mm}$ and the gas pressure can be adjusted between 4 and 20 bar. The distance between the nozzle and the workpiece is positioned by the z-linear drive to $0.3 \mathrm{~mm}$. The specified laser emission wavelength is $1070 \mathrm{~nm}$ in conjunction with a beam propagation factor of $\mathrm{M}^{2}<1.1$. The raw beam diameter of $7.25 \mathrm{~mm}$ is focused by a lens with focal length of $50 \mathrm{~mm}$. The resulting Rayleigh length and the focus diameter are calculated to $70 \mu \mathrm{m}$ and $11 \mu \mathrm{m}$, respectively. The Laser system is equipped with a position synchronous output (PSO) to modulate the laser digitally. The maximum digital modulation frequency for the laser is $50 \mathrm{kHz}$. Using the PSO, the laser is switched on for an adjustable time after the drives moved a given distance. With the PSO the energy input per unit length is kept constant during acceleration and deceleration paths (i.e. during cutting a corner).

To compare cutting results with traditional $\mathrm{CO}_{2}$ lasers, a $200 \mathrm{~W} \mathrm{CO}_{2}$ laser system (Synrad) is used. The system consists of 3-D linear stages (Aerotech) with a maximum velocity of $500 \mathrm{~mm} / \mathrm{s}$. The assist gas nitrogen flows through a coaxial nozzle with $0.5 \mathrm{~mm}$ diameter to the workpiece. The laser emits a beam with $11.7 \mathrm{~mm}$ diameter and a $\mathrm{M}^{2}$ of 1.2. The beam is focus in a Precitec cutting head with a $50 \mathrm{~mm}$ focal length. The focus diameter is calculated to $70 \mu \mathrm{m}$ with a Rayleigh length of $300 \mu \mathrm{m}$.

\subsection{Ceramic Material}

For our study, commercially available alumina sheets (CeramTec) having a thickness of $0.63 \mathrm{~mm}$ are used, a thickness which is most common in the electronic industry. The material is specified by a compositional purity of larger than $98 \%$, a density of $3.8 \mathrm{~g} / \mathrm{cm}^{3}$, a Vickers hardness HV1 of 1600 and a linear thermal expansion coefficient of $7.2 \times 10^{-6} \mathrm{~K}^{-1}$, respectively. The flexural strength is specified to $390 \mathrm{MPa}$ in conjunction with a Weibull modulus of 10 . In order to run bending tests, these ceramic sheets are laser cut into $24 \mathrm{~mm}$ long and $3 \mathrm{~mm}$ wide samples. For this cutting process also the optical properties are of importance. At the wavelength of the employed fiber laser $(1070 \mathrm{~nm})$ alumina has a high reflectance of $79 \%$ at room temperature [14]. More important, however, than the reflectance at room temperature (contributing only to the cut-in phase) is the absorption of hot and molten alumina during laser cutting. For this reason Zhang and Modest [15] published experimental results showing that alumina has an absorption higher than $90 \%$ around $1064 \mathrm{~nm}$ at temperatures higher than the melting point. Please note that in contrast to $1064 \mathrm{~nm}$ the absorption around $10600 \mathrm{~nm}$ (i.e. the of the $\mathrm{CO}_{2}$ radiation wavelength) in alumina is about $95 \%$ [16].

\subsection{Flexural strength measurement}

To measure the flexural strength, a 3-point bending test machine (Thuemler) is used with $20 \mathrm{~mm}$ distance between the two contact points. The flexural strength $\sigma$ is calculated with formula (1) from the maximum force $F$ which the sample withstands before braking. Here $l$ is the distance between the two contact points, $b$ stands for the width of the sample and $d$ expresses the sample thickness. The velocity of the bending test is set to $1 \mathrm{~mm} / \mathrm{min}$ like recommended by Bengisu [2].

$\sigma=\frac{3 \cdot \mathbf{F} \cdot \mathbf{l}}{2 \cdot \mathbf{b} \cdot \mathbf{d}^{2}}$

In contrast to metals, where the strength is Gaussian distributed, for ceramics it is Weibull distributed. In ceramics a failure in one region can't get compensated due to the lack of ductility. As a consequence the strength of ceramics is described as the minimum strength of all filaments in the material due to the lack of ductility [17]. This extreme value behavior is described well with the Weibull distribution.

Opposite to the 4 point bending test, in which a constant stress between the two inner points is provided, the stress in the 3 point bending test geometry is concentrated in a small area around the middle point [2]. This results to a smaller stressed volume in the 3 point test geometry and as a consequence to a lower probability of having a weak filament within this area. Therefore, the flexural strength in a 3 point bending test is typically higher as compared to a 4 point bending test.

\section{Results}

\subsection{Reference cut with scribe and break}

For comparison reasons sample geometries $\left(24 \times 3 \mathrm{~mm}^{2}\right)$ of alumina were produced by the scribe and break method. Using a $20 \mathrm{~W}$ pulsed fiber laser at $1 \mathrm{~mJ}$ pulse energy and $20 \mathrm{kHz}$ pulse frequency the sample is scribed in a multi pass process about 130 microns deep. Afterwards the scribed ceramic is broken mechanically. Figure 1 shows the braked edge after scribing where no cracks can be seen on the braking edge. The flexural strength of this samples is 
measured to $520 \mathrm{MPa}$ which is significantly higher than the specified value of $390 \mathrm{MPa}$, given by the supplier.

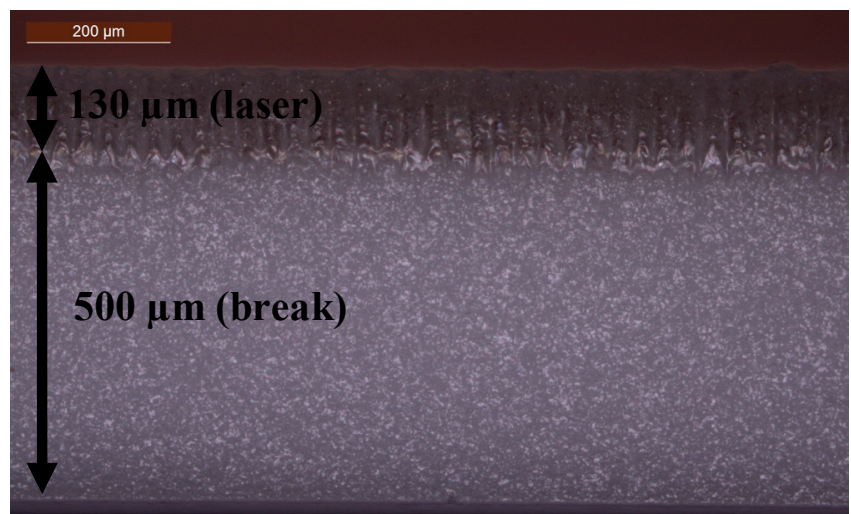

Figure 1: Braked edge after scribing with pulse laser.

\subsection{Fusion cutting using $\mathrm{CO}_{2}$ laser}

In this section, the influence of fusion cutting with a continuous wave $\mathrm{CO}_{2}$ laser on the flexural strength of the ceramic is evaluated. The $\mathrm{CO}_{2}$ laser operates at $200 \mathrm{~W}$ and the distance between nozzle and workpiece is set to $0.5 \mathrm{~mm}$. The focus position is placed onto the surface of the ceramic. At a velocity of $20 \mathrm{~mm} / \mathrm{s}$ and 8 bar gas pressure a cut without mechanical breakup is achieved. Figure 2 shows the cutting edge processed with the $\mathrm{CO}_{2}$ laser at $20 \mathrm{~mm} / \mathrm{s}$. The thickness of the glassy phase at the cut kerf is measured between $10 \mu \mathrm{m}$ and $40 \mu \mathrm{m}$. The flexural strength of the samples strongly depends on the cutting velocity. At $5 \mathrm{~mm} / \mathrm{s}$ a flexural strength of $188 \mathrm{MPa}$ is measured, at $10 \mathrm{~mm} / \mathrm{s}$ the flexural strength increases to $281 \mathrm{MPa}$ and reach a maximum of $311 \mathrm{MPa}$ at $20 \mathrm{~mm} / \mathrm{s}$. It is assumed that at higher velocities the laser dwell time at one point is lower which results in less heat diffusion into the material. As a result, the crack depth is reduced and as a consequence the mechanical strength increases. When cutting with $\mathrm{CO}_{2}$ laser at $20 \mathrm{~mm} / \mathrm{s}$ the strength of alumina decreases by $40 \%$ as compared to scribe and break. The energy input per unit length is $10 \mathrm{~J} / \mathrm{mm}$ which is halve of the track energy that Yilbas et al. [10] used for cutting $1.5 \mathrm{~mm}$ thick alumina $(2 \mathrm{~kW} \mathrm{CO}$ laser at $100 \mathrm{~mm} / \mathrm{s})$. In contrast, Huehnlein et al. [18] required only $1.5 \mathrm{~J} / \mathrm{mm}$ for cutting $0.25 \mathrm{~mm}$ alumina with a $\mathrm{CO}_{2}$ laser $(180 \mathrm{~W}$ at $120 \mathrm{~mm} / \mathrm{s})$.

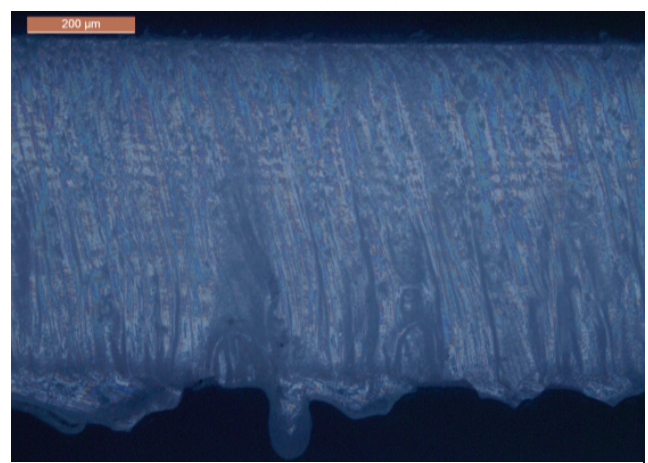

Figure 2: Cutting edge cut with $\mathrm{CO}_{2}$ laser at $20 \mathrm{~mm} / \mathrm{s}$

\subsection{Fusion cutting using continuous wave fiber laser}

To evaluate the influence of different machine parameters a linear experimental design, described by Siebertz et al. [19], with 4 parameters (shown in Table 1) and 16 experiments is run. A similar design setup is often used for optimizing laser processes, e.g. by Dhupal et al. [20] to optimize micro grooving of aluminum titanate or by Yang et al. [21] to analyze cutting of PMMA. To achieve high productivity the laser power is fixed to the maximum of $500 \mathrm{~W}$. The flexural strength is measured for every parameter combination and the influences of the laser parameters, shown in Table 1, are calculated with commercial statistics software (JMP $®)$. In this analysis, those parameter combinations resulting in a breakup during cutting are valuated with $0 \mathrm{MPa}$. Table 1 shows that the position of the focus has the most important influence on the flexural strength. The negative value of this influence expresses a higher strength at lower focus positions (a negative focus position indicates a focus position below the surface of the workpiece). In contrast, the velocity has no significant influence within the analyzed interval. The negative influences of the nozzle diameter and gas pressure reveal that too much gas leads to lower strength. Possible reasons are the mechanical force of the gas on the cut kerf and the

Table 1: Influence of laser parameters on the flexural strength. A negative influence expresses a strength reduction with increasing parameter value

\begin{tabular}{lll}
\hline Parameter & $\begin{array}{l}\text { Parameter } \\
\text { Space }\end{array}$ & $\begin{array}{l}\text { Influence } \\
\text { on strength }\end{array}$ \\
\hline Position of focus & $\begin{array}{l}-0.5 \mathrm{~mm} \text { to } \\
-0.1 \mathrm{~mm}\end{array}$ & $-63 \mathrm{MPa}$ \\
& $0.3 \mathrm{~mm}$ to & \\
Nozzle diameter & $0.8 \mathrm{~mm}$ & $-29 \mathrm{MPa}$ \\
Gas pressure & $6 \mathrm{bar} \mathrm{to}$ & $-23 \mathrm{MPa}$ \\
& $12 \mathrm{bar}$ & \\
Velocity & $50 \mathrm{~mm} / \mathrm{s} \mathrm{to}$ & $-0.5 \mathrm{MPa}$ \\
\hline
\end{tabular}

amount of re-solidifying melt.

Figure 3 shows the influence of the focus position and the gas pressure on the flexural strength graphically in a surface plot. It can be seen that the highest strength is achieved at low gas pressure and a low focus position. Further it is shown that the strength decreases with increasing focus position and gas pressure, which is expressed in Table 1 by the negative influences. At different parameter combinations, the crack network looks very different with respect to the distance between cracks, their orientation, curvature and visibility of the cracks because they are covered with re-solidified melt. In our study, a correlation between the shape of the crack network and flexural strength wasn't found. A possible reason for that is given by Modest [22] who simulated thermal stress during $\mathrm{CO}_{2}$ laser drilling of SiC. He found that the cracks seen at the surface only pervades a very thin layer near the process zone. In contrast, 
he assumes that the high temperature gradients which cause tensile stress are responsible for cracks below the surface result in mechanical breakup.

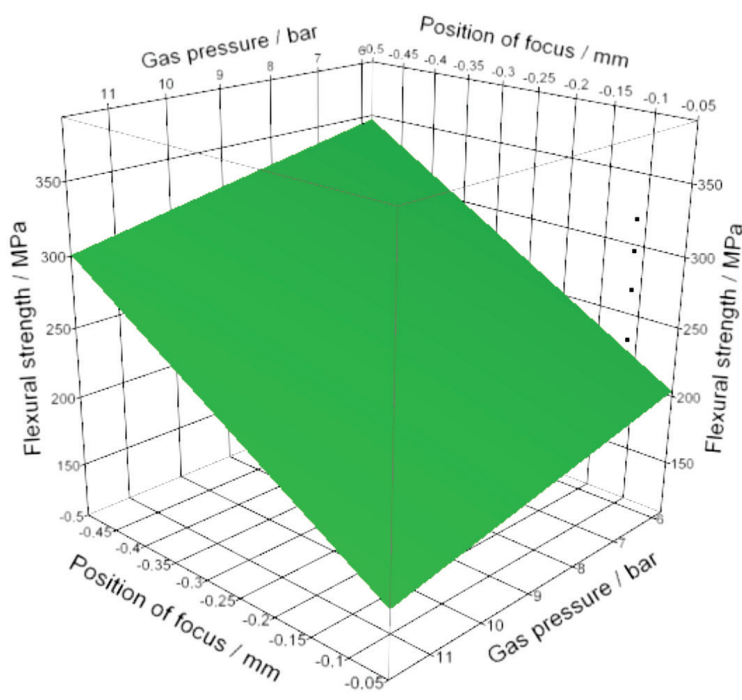

Figure 3: Contour plot of the flexural strength as a function of focus position and gas pressure in cw fiber laser cutting

The maximum flexural strength measured in these experiments of $395 \mathrm{MPa}$ is achieved with the parameter combination velocity $300 \mathrm{~mm} / \mathrm{s}$, gas pressure 6 bar, position of focus $0.5 \mathrm{~mm}$ below workpiece surface and nozzle diameter $0.8 \mathrm{~mm}$. Please note, that the position of the focus (calculated to $11 \mu \mathrm{m}$ diameter) is only $0.13 \mathrm{~mm}$ above the bottom of the substrate. Due to the short focal length of the lens the beam expands to $72 \mu \mathrm{m}$ at the surface. The flexural strength value of $395 \mathrm{MPa}$ is as high as the specification of $390 \mathrm{MPa}$, yet lower than the value determined by scribe and break. This parameter combination results in an energy input per unit length of $1.7 \mathrm{~J} / \mathrm{mm}$ at $300 \mathrm{~mm} / \mathrm{s}$ and $500 \mathrm{~W}$. This is less than $2.5 \mathrm{~J} / \mathrm{mm}$ Huehnlein et al. [18] applied for cutting $0.25 \mathrm{~mm}$ alumina with a single mode fiber laser $(250 \mathrm{~W}$ at $100 \mathrm{~mm} / \mathrm{s})$. Compared to $\mathrm{CO}_{2}$ laser cutting in section 3.2 where a track energy of $10 \mathrm{~J} / \mathrm{mm}$ is required the energy input per unit length for fiber laser cutting is much lower due to the smaller focus diameter.

Figure 4 shows the cutting edge of alumina with a parameter combination similar to that leading to the highest flexural strength, however with a lower cutting velocity of

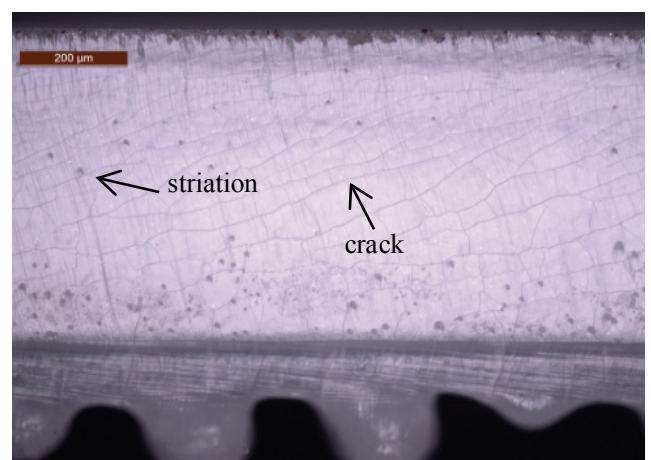

Figure 4: Cutting edge produced by $\mathrm{cw}$ fiber laser cutting
$100 \mathrm{~mm} / \mathrm{s}$ and a smaller nozzle diameter. In this regime the crack network can be clearly seen. The re-solidified melt forms a glassy phase with a thickness of a few microns. The thickness is measured with depth of sharpness method by focusing with the microscope on the striations and then focusing on the crack network in the ceramic. The distance between these two focus levels is the thickness of the glassy phase. The striations in the glassy phase are always perpendicular to the cracks. In Figure 4 the striations are parallel with an angle of $15^{\circ}$ to the vertical. At higher velocities of $300 \mathrm{~mm} / \mathrm{s}$ the striations get swirled and therefore the crack network changes its shape. Here it should be considered that alumina has a 2 to 3 orders of magnitude higher viscosity at melt temperature than steel [23]. Based on thermal simulations, Yilbas et. al. [10] found that cracks are caused by the re-solidification of the glassy phase. The re-solidification generates different forces parallel and perpendicular to the striations. This complements with the cracks in Figure 4 being perpendicular to the striations.

To measure the width of the cracks a scanning electron microscope (SEM) with an acceleration voltage of $10 \mathrm{kV}$ is used. The cracks in Figure 5 are measured to a width between 0.1 microns and 1 micron. This is still below the mean grain size given by the manufacturer between 2 microns to 5 microns. Usually the depth of the cracks is much higher than the width. As a result the cracks can be deeper than the grain size which leads to significant influences on the strength.

According to the Griffith equation [24] the stress for a brittle fracutre $\sigma_{c}$ of materials with cracks can be calculated with formula (2) from the elastic modulus $\mathrm{E}$ and the specific surface energy $\gamma$.

$$
\sigma_{c}=\sqrt{\frac{2 * \gamma * E}{\pi * c}}
$$

With increasing crack depth $\mathrm{c}$ the stress for a brittle fracture caused by cracks decreases. When this stress falls below the specified flexural strength of the material, the measured strength also decreases. It is assumed that the cracks in $\mathrm{cw}$ fiber laser cutting are deep enougth to influence the flexural strength. In $\mathrm{CO}_{2}$ laser cutting, the flexural strength is lower compared to fiber laser cutting, which can be explainded by deeper cracks which are obscured by re-solidified melt.

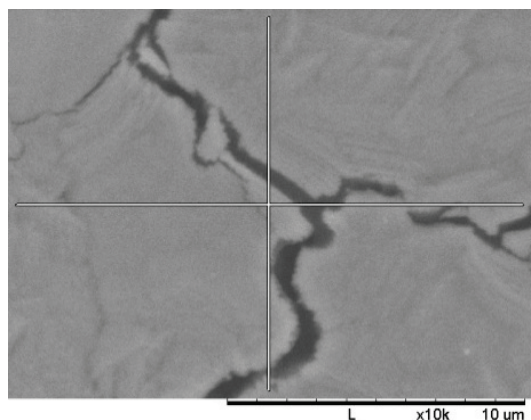

Figure 5: SEM image of cracks caused by cw cutting 


\subsection{Fusion cutting using modulated fiber laser}

In order to cut small contours, the linear drives of the laser system have to decelerate before and accelerate behind corners. Therefore, the velocity of $300 \mathrm{~mm} / \mathrm{s}$ cannot be held. As a consequence, the energy input per unit length sharply rises at corners. This high energy input in combination with the disadvantage that corners generally weaken the strength of ceramics results in a mechanical breakup of the substrate. To avoid this, the laser is digitally modulated to keep the energy input per unit length constant. Using a velocity of $1 \mathrm{~mm} / \mathrm{s}$ and a switch on time of $1 \mathrm{~ms}$ after the drives travel $10 \mu \mathrm{m}$ even small and complex contours are cut without breakup (other parameters: position of focus $0.5 \mathrm{~mm}$, gas pressure $6 \mathrm{bar}$, nozzle diameter $0.3 \mathrm{~mm}$, laser power $500 \mathrm{~W}$ ). The travel distance is chosen with respect to the focus diameter of $11 \mu \mathrm{m}$. The energy input per unit length is calculated from the pulse energy of $0.5 \mathrm{~J}(500 \mathrm{~W}$ for $1 \mathrm{~ms}$ ) which occurs after a travel distance of $10 \mu \mathrm{m}$ (100 pulses per $\mathrm{mm}$ ) to $50 \mathrm{~J} / \mathrm{mm}$. This is much higher than $1.7 \mathrm{~J} / \mathrm{mm}$ when cutting straight lines in continuous wave mode. The reason for thigh energy input per unit length is the cooling of the process zone between two pulses and the therefore lower absorption for the following pulse. A further reason is the thermal conduction that takes more energy away from the process zone at slower velocities.

Figure 6 shows the cutting edge of a digitally modulated cut where the striations at the upper third have a width of about $10 \mu \mathrm{m}$ that equates the distance between two laser pulses. Due to the surface roughness the re-solidified melt is haze, so possible existing cracks cannot be seen. For instance, a flexural strength of $506 \mathrm{MPa}$ is achieved for cuts using digital modulation which is almost as high as the value for scribe and break. This high strength achieved at low pulse frequency of $100 \mathrm{~Hz}$ and $10 \%$ duty cycle corresponds with the results of Yan et al. [11]. The Weibull modulus for this parameter combination is calculated to 29 . As a result of the relatively low gas pressure and the narrow cut kerf of about $40 \mu \mathrm{m}$, the kerf is closed partially at the lower edge by the dross. To separate the sample from the substrate the samples can be pushed out easily by hand.

In terms of higher productivity it is not recommended to further increase the velocity in this parameter combination even at constant track energy. At higher velocities of

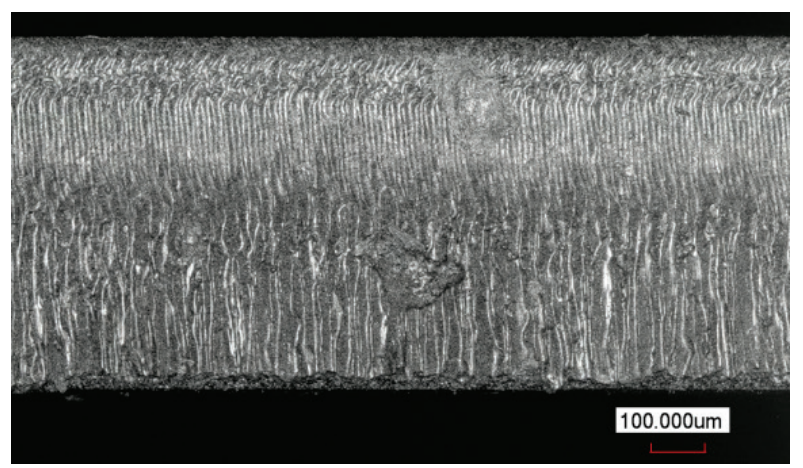

Figure 6: Laser scanning image of cutting edge by digitally modulated cutting at $1 \mathrm{~mm} / \mathrm{s}$
$3 \mathrm{~mm} / \mathrm{s}$ the flexural strength is reduced by about $20 \%$ to $398 \mathrm{MPa}$ keeping the other parameters constant. To keep the strength high even at higher velocities requires to either reduce the pulse duration or to increase the distance between the pulses. A reduction of the pulse duration results in an incomplete cut because the power density is too low to melt the ceramic. On the other hand increasing the travel distance between two pulses to $40 \mu \mathrm{m}$ and therefore reduce the track energy to $12 \mathrm{~J} / \mathrm{mm}$ a cutting velocity of $10 \mathrm{~mm} / \mathrm{s}$ is possible. With this parameter combination and a gas pressure of 14 bar a flexural strength of $469 \mathrm{MPa}$ is achieved and the samples are separated completely from the substrate. The benefit of a ten times higher productivity results in a flexural strength reduction of $8 \%$ compared to the cut at $1 \mathrm{~mm} / \mathrm{s}$ and a decrease of $10 \%$ compared to scribe and break. The cutting edge achieved with this parameter combination is shown in Figure 7. The striations width of $40 \mu \mathrm{m}$ is as wide as the travel distance between two pulses. The surface roughness is measured to $3.1 \mu \mathrm{m}$ and therefore similar to the cut at $1 \mathrm{~mm} / \mathrm{s}$.

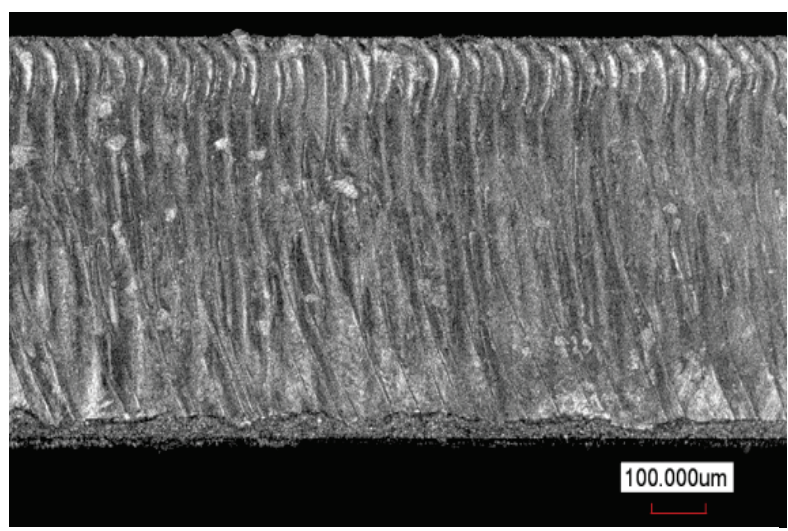

Figure 7: Laser scanning image of cutting edge by digitally modulated cutting at $10 \mathrm{~mm} / \mathrm{s}$

To show the ability of cutting complex contours a test design with sharp edges and inner circles is cut. With both parameter combinations the test pattern was cut successfully with high quality. Figure 8 shows a part of this test pattern cut with digital modulation using a velocity of $10 \mathrm{~mm} / \mathrm{s}$ and $40 \mu \mathrm{m}$ pulse distance.

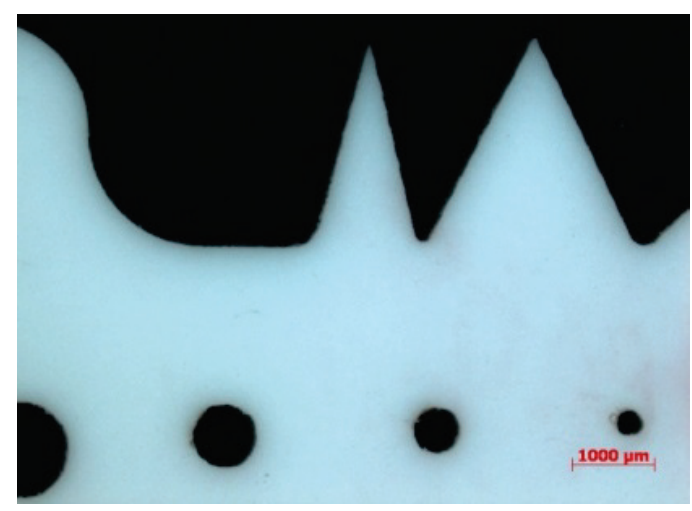

Figure 8: Complex contour cut with $10 \mathrm{~mm} / \mathrm{s}$ with holes between $0.3 \mathrm{~mm}$ and $1.1 \mathrm{~mm}$ and sharp angles of $30^{\circ}$ and $50^{\circ}$ 


\subsection{Influence of the outer contours}

In some applications it is necessary to fit the geometry of the substrate to the available space. Therefore in these cases, the substrates need complex outer contours. The designed geometry for this study is shown in Figure 10. On the left hand side the geometry has a width of $3 \mathrm{~mm}$. This is as wide as in the previous experiments. On the right hand side the pattern is one mm wider than on the left. The diminution in the middle is designed with different radii. In the bending machine the pattern is placed with the diminution directly at the middle bending point.

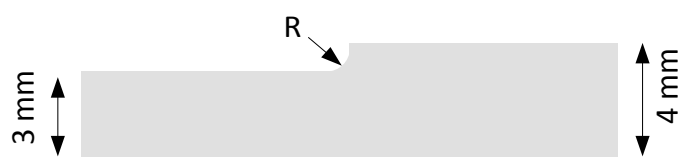

Figure 9: Test pattern for outer contours with variable rounding

The parameters used in this cut are described in section 3.4 with a velocity of $1 \mathrm{~mm} / \mathrm{s}$, distance between two pulses of $10 \mu \mathrm{m}$ and $1 \mathrm{~ms}$ pulse duration (other parameters: position of focus $-0.5 \mathrm{~mm}$, gas pressure $6 \mathrm{bar}$, nozzle diameter $0.3 \mathrm{~mm}$, pulse peak laser power $500 \mathrm{~W}$ ). For the calculation of the flexural strength the smaller width $(3 \mathrm{~mm})$ is used. Figure 11 shows the flexural strength as a function of the radius $\mathrm{R}$ compared to the reference cut with the same parameter combination from section 3.4. It is obvious that the test pattern, even with a large radius, has a much lower flexural strength than the reference cut. A reason for this is the concentration of the force from the wider part of the sample on the diminution and the general weakness of ceramics at corners. A further effect in corners is the higher thermal load which leads to higher thermal induced stress. Figure 11 also reveals a high reduction of the strength at radii smaller than $0.1 \mathrm{~mm}$. This corresponds with the results of Glaw et al. [25] showing the corner rounding can increase the resistance of a breakup during temperature changes.

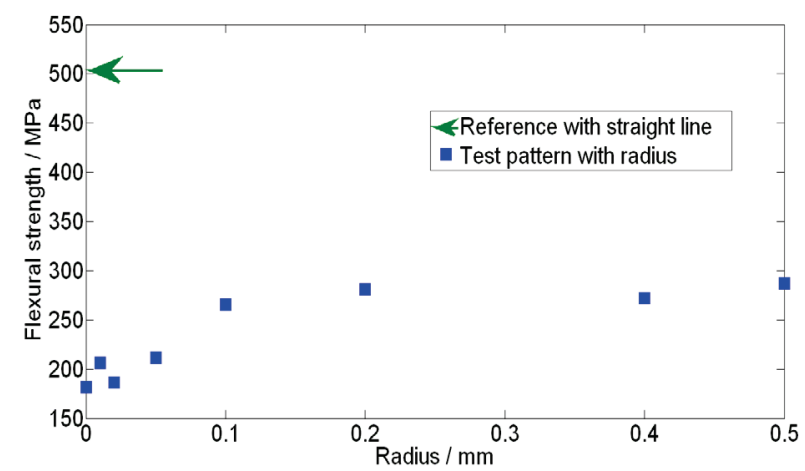

Figure 10: Flexural strength as a function of the rounding radius

\subsection{Influence of inner contours}

In hybrid circuits it is also necessary to cut holes for vias or mounting purposes. This section is about the influences of different inner contours on the flexural strength of ceramic material. Four test patterns are designed as shown in Figure 9. The width of all samples is $4 \mathrm{~mm}$ and the inner contours reduce the width in the middle by $1 \mathrm{~mm}$. Howev$\mathrm{er}$, for the calculation of the flexural strength the effective width of $3 \mathrm{~mm}$ is used. The parameter combination used for the experiments is the same than in section 3.5 for the outer contours.

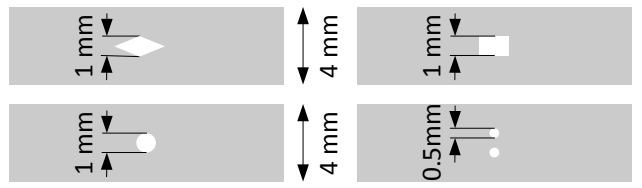

Figure 11: Test pattern for different inner contours

Figure 12 shows the flexural strength of the test pattern compared with the reference cut from section 3.4 using the same parameter combination. The lowest strength is measured cutting a rhombus into the ceramic. In this design the force of the bending machine is focused to the peaks of the rhombus. Due to the lack of ductility the material cannot compensate the stress and results in a breakup. The flexural strength of the sample with the rectangle is $16 \%$ higher than that with the rhombus. The samples break at the corners of the inner rectangle rather than in middle of the rectangle where in a homogeneous material the highest stress results. This corresponds to the results shown in section 3.5 , where also the weakness of corners is revealed. Cutting a circle results in the highest flexural strength measured due to the lack of inner corners but the strength is still lower than the reference of the $3 \mathrm{~mm}$ wide rectangle. These results show the weakening of alumina structures by inner contours especially inner contours with corners.

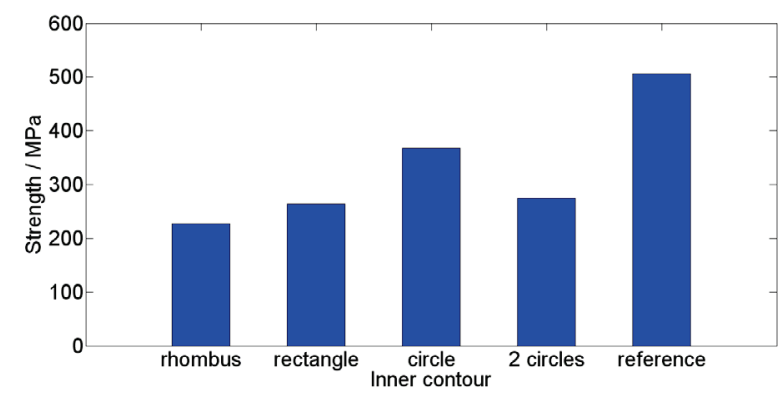

Figure 12: Flexural strength by cutting different inner contours

\section{Conclusion}

In this contribution the influence of cutting $0.63 \mathrm{~mm}$ thick alumina with single mode fiber laser and $\mathrm{CO}_{2}$ on the flexural strength of the material is analyzed. For these experiments samples with a length of $24 \mathrm{~mm}$ and a width of $3 \mathrm{~mm}$ are cut and the flexural strength is measured with a 3 point bending test. The results using design of experiments show that the position of the focus has a large and the gas 
pressure and nozzle diameter a medium influence on the strength. To cut smaller contours a digital modulation is used to avoid a mechanical breakup of the ceramic. An overview of the flexural strength with different cutting methods is shown in Table 2.

Further results show that additional outer contours can halve the strength and the lack of rounding further amplifies this effect. Inner contours especially with corner are also decreasing the strength drastically while an inner circle causes the lowest strength reduction.

Table 2: Overview about the strength at different cut methods

\begin{tabular}{lcc}
\hline \multicolumn{1}{c}{ Modus } & Velocity & Strength \\
\hline $\begin{array}{l}\text { Reference by scribe and } \\
\text { break }\end{array}$ & $520 \mathrm{MPa}$ \\
Continuous wave $\mathrm{CO}_{2}$ & $20 \mathrm{~mm} / \mathrm{s}$ & $311 \mathrm{MPa}$ \\
$\begin{array}{l}\text { Continuous wave } \\
\text { fiber laser }\end{array}$ & $300 \mathrm{~mm} / \mathrm{s}$ & $395 \mathrm{MPa}$ \\
$\begin{array}{l}\text { Modulated fiber laser } \\
10 \mu \mathrm{m} \text { pulse distance }\end{array}$ & $1 \mathrm{~mm} / \mathrm{s}$ & $506 \mathrm{MPa}$ \\
$\begin{array}{l}\text { Modulated fiber laser } \\
40 \mu \mathrm{m} \text { pulse distance }\end{array}$ & $10 \mathrm{~mm} / \mathrm{s}$ & $469 \mathrm{MPa}$ \\
\hline
\end{tabular}

\section{References}

[1] "Typial Properties of Technical Ceramics," Information Center Technical Ceramic, 2013. [Online]. Available: www.keramverband.de.

[2] M. Bengisu, Engineering Ceramics, Berlin: Springer, 2001.

[3] K. Li and P. Sheng, "Plane Stress Model for Fracture of Caramics during Laser Cutting," International jorunal of machine tools \& manufacture, pp. 14931506, 11351995.

[4] A. Samant and N. Dahotre, "Laser machining of structural ceramics-A review," Journal of the European Ceramic Society 29 (2009) ., p. 969-993, 29 2009.

[5] I. Black and K. Chua, "Laser cutting of thick ceramic tile," Optics \& Laser Technology, pp. 193-205, 429 1999.

[6] L. Hong, L. Lic and C. Ju, "A study of laser cutting engineering ceramics," Optics \& Laser Technology, pp. 531-538, 311999.

[7] L. Ji, Y. Yan, Y. Bao and Y. Jian, "Laser crack-free cutting technique for thick and dense ceramics," Conference on Lasers and Electro-Optics, pp. 4244-
3830-3/09, 978-1 2009.

[8] L. Wee, P. Crouse and L. Li, "A statistical analysis of striation formation during laser cutting of ceramics," International Journal of Advanced Manufacturing Technology, p. 699-706, 362008.

[9] S. Lee S and S. Ahn, "A Probabilistic Model for Crack Formation in Laser Cutting of Ceramics," JSME international journal Series, pp. 1591-1597, 46/3 2003.

[10] B. Yilbas, S. Akhtar and C. Karatas, "Laser straight cutting of alumina tiles: thermal stress analysis," International Journal of Advanced Manufacturing Technology, p. 1019-1030, 582012.

[11] Y. Yan, L. Ji, Y. Bao, X. Chen and Y. Jiang, "CO2 laser high-speed crack-free cutting of thick-section alumina based on close-piercing lapping technique," The International Journal of Advanced Manufacturing Technology, pp. 1611-1624, 642013.

[12] X. Wang, H. Zheng, P. Chu, J. Tan, K. Teh, T. Liu, C. Ang and G. Tay, "Femtosecond laser drilling of alumina ceramic substrates," Applied Physics A, pp. 271-278, 1012010.

[13] J. Lump and S. Allen, "Excimer Laser Machining and Metallization of Vias in Aluminum Nitride," TRANSACTIONS ON COMPONENTS, PACKAGING, AND MANUFACTURING TECHNOLOGY, pp. 241246, 20/3 1997.

[14] W. Liu , W. Du and J. Liao , "Application of fiber laser used in the field of stent cutting and micromachining," Lasers in Material Processing and Manufacturing, pp. 263-270, 56292005.

[15] Z. Zhang and M. Modest, "Temperature-Dependent Absorptances of Ceramics for Nd:YAG and CO2 Laser Processing Applications," Proceedings of the Materials Processing Cutting Symposium ICALEO, pp. 29-38, 81C 1996.

[16] R. Molian, P. Shrotriya and P. Molian, "Thermal stress fracture mode of CO2 laser cutting," International Journal of Advanced Manufacturing Technology, p. 725-733, 392007.

[17] H. Schaumburg, Keramik, Stuttgart: Teubner, 1994.

[18] K. Huehnlein, K. Tschirpke and R. Hellmann, "Optimization of laser cutting processes using design of experiments," Physics Procedia, pp. 243-252, 5 2010.

[19] L. Siebertz, D. van Bebber and T. Hochkirchen, Design Of Experiments, Berlin Heidelberg: Springer, 2010.

[20] D. Dhupal, B. Doloi and B. Bhattacharyya, "Parametric analysis and optimization of $\mathrm{Nd}: \mathrm{YAG}$ laser micro-grooving of aluminum titanate $\mathrm{Al} 2 \mathrm{TiO} 5$ ceramics," International Journal of Advanced Manufacturing Technology, p. 883-893, 362012.

[21] C. Yang, C. Deng and H. Chiang, "Combining the Taguchi method with artificial neural network to construct a prediction model of a $\mathrm{CO} 2$ laser cutting experiment," International Journal of Advanced Manufacturing Technology, p. 1103-1111, 592012. 
[22] M. Modest, "Transient elastic and viscoelastic thermal stresses during laser drilling of ceramics," Heat Transfer, pp. 892-898, 1201998.

[23] F. Quintero , J. Pou , F. Lusquinos and M. Lar, "Cutting of ceramic plates by optical fiber guided Nd:YAG laser," Journal of Laser Application, pp. 8488, 2132001.

[24] S. Vahaviolos, "Real Time Detection of Microcracks in Brittle Materials Using Stress Wave Emission (SWE)," IEEE Transactions on Parts, Hybrids and Packaging, pp. 152-159, 3101974.

[25] V. Glaw, R. Hahn, A. Paredes and U. Hein, "Laser Machining of Ceramics and Silicon for MCM-D Applications," International Symposium on Advanced Packaging Materials, pp. 173-176, 1997.

[26] C. Tsai and H. Chen, "Laser milling of cavity in ceramic substrate by fracture-machining element technique," Journal of materials processing technology, pp. 158-165, 2003.

(Received: August 19, 2013, Accepted: May 13, 2014) 